\title{
Hand washing knowledge and practice among school going children in Duwakot, Bhaktapur: A cross sectional study
}

\section{Manandhar P', Chandyo RK}

1Pratibha Manandhar, Lecturer; ${ }^{2}$ Ram Krishna Chandyo, Assistant Professor, Department of Community Medicine, Kathmandu Medical College, Duwakot

\begin{abstract}
Backg ro und: Diarrhea and acute respiratory tract infection are the commonest cause of morbidity and mortality in Nepal. Proper hand washing techniques help to reduce the incidence of diarrhea and acute respiratory infection in children. Objective: Objective of this study was to identify hand washing knowledge and practice among school children of Duwakot, Bhaktapur.

Methodology: This was a cross-sectional study conducted among 340 students of grade V, VI and VII from both the government and private schools of Duwakot, Bhaktapur. Convenient sampling technique was applied in government schools (due to less number of students) whereas students were randomly selected from private school (due to large number).

Result: All the students had knowledge about the hand washing technique before meal and after defecation. Almost all (99.4\%) students reported that they wash hand before meal and $92.4 \%$ students reported that they practiced hand washing after defecation. But, only $8.5 \%$ students at school and $47 \%$ students at home regularly washed hand with soap and water. However $91.6 \%$ students at school and $81 \%$ students at home washed hand only by water due to unavailability of soap.

Conclusion: Although students had hand washing knowledge; proper hand washing practices was lagging behind.
\end{abstract}

Key words: Hand washing, Knowledge, Practice

\section{INIR:ODUCTION}

ygiene promotion enhances the effectiveness of water and sanitation programme in most of the developing countries ${ }^{1}$. Promoting hygiene practices is imperative for preventing a number of communicable diseases. Diarrhea and acute respiratory tract infections (ARI) are the most common cause of morbidity and mortality particularly among children in a developing country like Nepal ${ }^{2,3}$. Due to poor hygiene, children are more vulnerable to have food and water borne diseases. Most of the pathogenic organisms that cause diarrhea are transmitted primarily or exclusively by the faecooral route. Faeco-oral transmission may be water-borne, food-borne or direct transmission, which implies an array of other faeco-oral routes such as via fingers, or fomites

Address for correspondence

Dr. Pratibha Manandhar

Lecturer

Department of Community Medicine,

Kathmandu Medical College,

Duwakot, Bhaktapur, Nepal

E-mail: drpratibhamanandhar@gmail.com or dirt which may be ingested by young children ${ }^{4}$. Hand hygiene is important in primary schools to prevent the spread of infectious illnesses and is a key infection control measure recommended during pandemic influenza ${ }^{5}$. Having knowledge about good practice of the hand washing with soap and water helps to prevent conditions like diarrhea, typhoid, hepatitis A or E.

Awareness on hand washing practice is one of the most important tools on preventing infectious diseases. Hand washing with soap and water before eating and after defecation can reduce the risk of diarrheal illnesses and other infectious diseases. Hand washing, which provides protection against communicable diseases, is promoted by the government of Nepal and included in the framework of the Nepal Health Sector Program $1{ }^{6}$. According to NDHS 2011, about half of households (48 percent) had soap and water at hand washing place, 16 percent had water and other cleansing agents (ash, mud, sand, etc.), 17 percent had only water, and two percent had soap but no water. Overall, 14 percent of households did not have water or any cleansing agent. 
In general, these households did not have a fixed designated place for hand washing? ${ }^{7}$. Catalina LopezQuintero et al in Bogotá, Colombia, found one third $(33.6 \%)$ of the research population practiced proper hand-washing behavior (i.e., washing hands "always" or "very often" with soap and clean water before eating and after using the toilet) $)^{8}$. As there are not enough studies on hand hygiene on school children, this study is formatted to comprehend the knowledge and practice about the hand washing among school children.

\section{METHOD}

This was a cross sectional study done among students of Grade V, VI and VII of government and private schools of Duwakot, Bhaktapur. Schools of Duwakot were purposively selected. Seven schools (three governments and four private) was included in this study. Owing to less number of students, all the students from the government schools were included in thisstudy. Whereas students were randomly selected(by odd and even roll number) in private schools due to the large number of students except one private school that consists of only three students in grade $\mathrm{V}$ and no students in grade $\mathrm{VI}$ and VII.

Students were provided self-generated pre-designed questionnaire to access knowledge and practice of hand washing which included the components of sanitation and hand washing. Questionnaire was translated in Nepali language before data collection. Data collection was done from $10^{\text {th }}$ June to $30^{\text {th }}$ June 2016 (3 weeks duration).

Data were entered in excel spreadsheet and analyzed using statistical software SPSS Version 18. Statistical analysis was performed in frequency and cross tabulation. Ethical clearance for the study was taken from Institutional Review Committee (IRC) of Kathmandu Medical College. Verbal consent was obtained from Principal/ Vice Principal of each school after explaining all the relevant details of the study. Written consent was obtained from all students in front of class teacher who participated in this study after being provided detail information and objectives of the study.

\section{RESULT}

The total of 340 students from seven schools (three governments and four private) were included in this study. Of the total, $271(80 \%)$ students were from private school and $69(20 \%)$ from government school. Of total, $172(51 \%)$ participants were boys and $168(49 \%)$ were girls. There were 122 students from grade V, 104 from grade VI and 114 were from grade VII. Majority of the students' mothers were housewives $224(66 \%)$ and fathers were service holder 175 (51.5\%). Likewise, most of their parents have higher secondary education status. (Table 1)

All thestudents(100\%)reported that they had knowledge about hand washing before meal and after defecation. Out of 340 students, 103(25.2\%) private school students and $63(82.9 \%)$ government school students had received hand washing knowledge from teachers. Similarly, 157 (38.4\%) private school and 6 (7.9\%) government school students had gathered hand washing knowledge from mother. Moreover, $83(20.3 \%)$ private and $4(5.3 \%)$ government school students obtained hand washing knowledge from father. 47 (11.5\%) private and 1 (1.3\%) government school students acquired hand washing knowledge from television, which were statistically significant shown in Table 2.

Of the total, $338(99.4 \%)$ students claimed that they did hand wash before meal and $314(92.4 \%)$ students washed their hand after defecation. Similarly, 314 (92.3\%) students used soap and water for hand washing before meal and $329(96.8 \%)$ students washed their hand after defecation (Table 3). But Only 8.5\% students at school and $48.1 \%$ students at home regularly hand washed with soap and water (Table 4). Of all the participated students, 259 (76.2\%) students at school and 177 (52\%) in home stated "sometimes not available" hand washing material (Table 4). 285 (91.6\%) students used plain water at school and $145(81 \%)$ at home for hand washing purposes. However, 52 (15.3\%) students at school and $2(0.5 \%)$ at home disclosed there were unavailability of soap for hand washing. Similarly, seven $(2.3 \%)$ at school and two $(1.1 \%)$ at home do not wash their hand due to lack of soap. This is further illustrated in Table 4. 
Manandhar $\mathrm{P}$ et al.

\section{Table1: Socio-demographic profile}

\begin{tabular}{|c|c|c|}
\hline & No. of students (N) & Percentage (\%) \\
\hline \multicolumn{3}{|l|}{ Schools } \\
\hline Private & 271 & 80 \\
\hline Government & 69 & 20 \\
\hline Total & 340 & 100 \\
\hline \multicolumn{3}{|l|}{ Sex of students } \\
\hline Male & 172 & 51 \\
\hline Female & 168 & 49 \\
\hline Total & 340 & 100 \\
\hline \multicolumn{3}{|l|}{ Class Standard } \\
\hline V & 122 & 36 \\
\hline VI & 104 & 30 \\
\hline VII & 114 & 34 \\
\hline Total & 340 & 100 \\
\hline \multicolumn{3}{|l|}{ Mother's Occupation } \\
\hline Housewife & 224 & 66 \\
\hline Traditional work & 42 & 12.4 \\
\hline Business & 25 & 7.4 \\
\hline Service & 27 & 7.8 \\
\hline Others & 22 & 6.4 \\
\hline Total & 340 & 100 \\
\hline \multicolumn{3}{|l|}{ Father's Occupation } \\
\hline Service & 175 & 51.5 \\
\hline Bussiness & 73 & 21.5 \\
\hline Others & 92 & 27 \\
\hline Total & 340 & 100 \\
\hline Mother's Education & $\mathrm{N}$ & $\%$ \\
\hline Illiterate & 46 & 13.5 \\
\hline Can read newspaper & 23 & 6.8 \\
\hline Primary education & 25 & 7.4 \\
\hline Secondary education & 55 & 16.2 \\
\hline Higher secondary education & 113 & 33.2 \\
\hline Bachelor & 9 & 2.6 \\
\hline Don't know & 69 & 20.3 \\
\hline Total & 340 & 100 \\
\hline \multicolumn{3}{|l|}{ Father's Education } \\
\hline Illiterate & 26 & 7.6 \\
\hline Can read newspaper & 22 & 6.5 \\
\hline Primary education & 23 & 6.8 \\
\hline Secondary education & 28 & 8.2 \\
\hline Higher secondary education & 162 & 47.6 \\
\hline Bachelor & 11 & 3.3 \\
\hline Don't know & 55 & 16.2 \\
\hline Total & 340 & 100 \\
\hline
\end{tabular}


Table 2: Hand Hygiene Knowledge among students

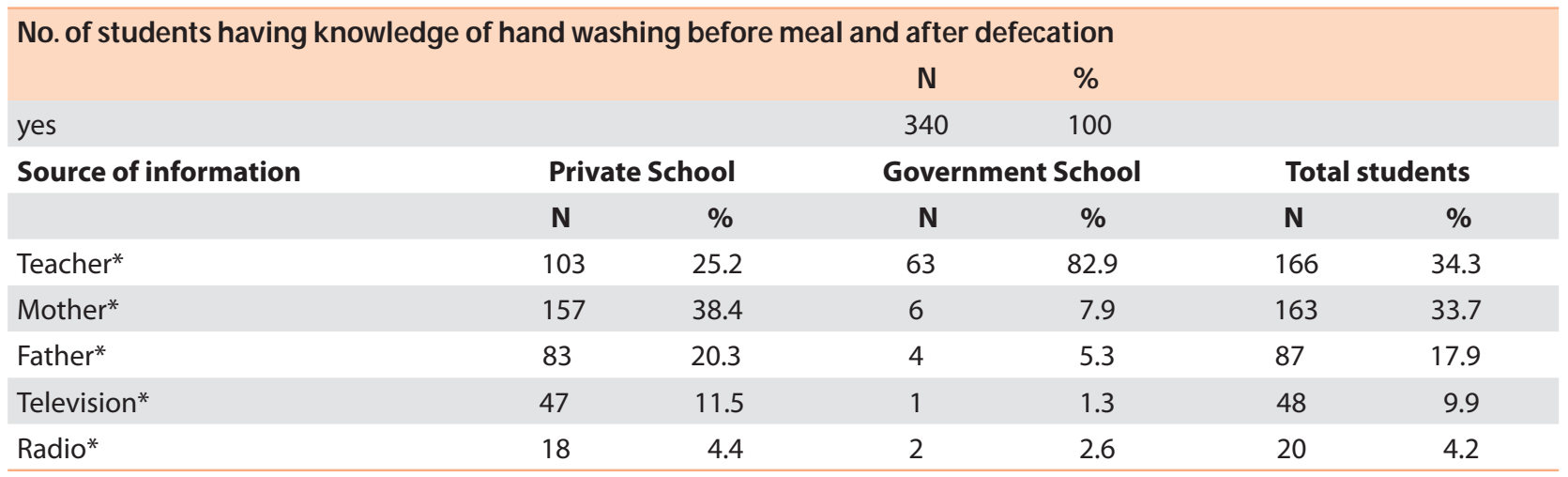

*Multiple responses

Table 3: Hand washing practice

\begin{tabular}{lcccc}
\hline Hand washing practices & \multicolumn{2}{c}{ Before meal } & \multicolumn{2}{c}{ After defecation } \\
Yes & $\mathbf{N}$ & $\%$ & $\mathbf{N}$ & 92.4 \\
\hline Sometimes I wash hand & 338 & 99.4 & 314 & 2.6 \\
\hline Sometime I forget to wash & 1 & 0.3 & 9 & 5 \\
\hline Total & 1 & $\mathbf{1 0 0}$ & $\mathbf{3 4 0}$ & $\mathbf{1 0 0}$ \\
Use of hand washing material & $\mathbf{3 4 0}$ & & 329 & 96.8 \\
\hline Soap & & 92.3 & 5 & 1.4 \\
\hline Ash & 314 & 0.9 & 6 & 1.8 \\
\hline Plain water & 3 & 6.8 & $\mathbf{3 4 0}$ & $\mathbf{1 0 0}$ \\
\hline Total & 23 & $\mathbf{1 0 0}$ & $\mathbf{3 4 0}$ \\
\hline
\end{tabular}

Table 4: Availability of soap in school and home

\begin{tabular}{|c|c|c|c|c|}
\hline \multirow{2}{*}{ Availability of soap } & \multicolumn{2}{|c|}{ School } & \multicolumn{2}{|c|}{ Home } \\
\hline & $\mathbf{N}$ & $\%$ & $\mathbf{N}$ & $\%$ \\
\hline Every time & 29 & 8.5 & 161 & 47.5 \\
\hline Sometime not available & 259 & 76.2 & 177 & 52.0 \\
\hline \multirow[t]{2}{*}{ Not available } & 52 & 15.3 & 2 & 0.5 \\
\hline & 340 & 100 & 340 & 100 \\
\hline \multicolumn{5}{|c|}{ If sometime, soap is not available as a hand washing material } \\
\hline Plain water & 285 & 91.6 & 145 & 81 \\
\hline Ash & 9 & 2.9 & 27 & 15.2 \\
\hline Mud & 10 & 3.2 & 5 & 2.8 \\
\hline I don't wash hand & 7 & 2.3 & 2 & 1 \\
\hline Total & 311 & 100 & 179 & 100 \\
\hline
\end{tabular}

\section{DISCUSSON}

Even though the students claimed to have theoretical hand washing knowledge, hand washing practices was seen only in few students. Students said that they washed their hand only with water when the soap was unavailable. Nevertheless, this may not prevent the diseases caused by contaminated hands.
A study done Mohammed G et al. in UAE showed 65\% students had adequate perception about personal hygiene ${ }^{10}$ which is quite similar to our finding. Likewise, another study conducted by Alyssa $\mathrm{V}$ et al. in Ethiopia reveled that $99 \%$ students reported hand washing before meal and $76.7 \%$ students washed their hand after defecation. Nevertheless, only $14.8 \%$ students 
really practiced in their daily activities ${ }^{11}$. By contrast, in our study $29(8.5 \%)$ students actually practiced hand washing in school and $47.5 \%$ washed their hand in home with soap and water. It was also noted in our study that $259(76.2 \%)$ of students at school and $177(52 \%)$ in home stated unavailability of soap for hand washing. Among those, $91.6 \%$ at school and $81 \%$ at home used plain water for hand washing and seven students $(2.3 \%)$ at school and two students (1\%) in home do not wash hand at all.

A study done in Columbia by Lopez QC showed 33.6\% of the students always wash their hands with clean water and soap before eating and after toilet. Author also indicated that students cannot develop healthy behaviors in many schools because of insufficient cleaning materials and other environmental factors ${ }^{8}$. A study done by Gawai $P$ et al from Mumbai, India mentioned that $75.5 \%$ students washed wash before eating food, after eating (51.1\%) and after toilet use $(18.1 \%)$. The author showed the majority of children $(91.5 \%)$ reported using soap for hand washing ${ }^{12}$. Similarly, in this study also majority of students (94.5\%) students used soap for hand washing. Whereas Ray SK et al observed very less hand washing rate especially with soap and water in his study (21.3\%) and $47.3 \%$ never used soap for hand washing as comparing in this study ${ }^{13}$. Takalkar A et al also found only $40.0 \%$ of the school children were practicing hand washing with soap and water and $41.2 \%$ had never used soap ${ }^{14}$.

Knowledge about hand washing does not always translate into practice and its consistency. A study done in Nigeria, where the pupils had good knowledge of hand washing practice but inadequate opportunities and lack of sanitation facilities at schools and homes did not allow them to practice the hand washing knowledge they had acquired ${ }^{15}$. In this study, despite $100 \%$ hand washing knowledge, more than half $(76.2 \%$ students at school and $52 \%$ in home) students described sometimes unavailability of hand washing material. As such, most students use plain water $(91.6 \%$ at school and $81 \%$ at home).

According to Water, Sanitation and Hygiene (WASH) Program by United Nations International Children Emergency Fund(UNICEF), ${ }^{16}$ the Government of Nepal has set its targets to achieve universal access to improve water supply and sanitation by 2017. One of the goals of this program is easy access for all children to child friendly schools with school WASH facilities. This study shows high percentage of hand washing knowledge which may have an impact of the awareness conducted by WASH program in the schools.

Regarding the consent issues, in case of children, consent of parents has to be taken. As this study inquired only about hand washing knowledge and practice without harming anybody mentally, physically and socially, with School Principal's permission, written consent was taken in front of class teacher after explaining about the study procedure and objectives to the student, teacher and Principal.

\section{CONAUSONS}

This study showed that students had hand washing knowledge but proper hand washing practices was sub optimal. Some students did hand wash by water only or some did not wash hand at all due to unavailability of hand washing material. However, proper environment should be created at school and at home for practicing hand washing before food and after defecation.

\section{REFERENGES}

1. Sijbesma C, Christoffers T. The value of hygiene promotion: cost effectiveness analysis of interventions in developing countries. Health Policy Plan. 2009;24(6):418-427.

2. Dhimal M, Dhakal P, Shrestha N, Baral K, Maskey $M$. Environmental burden of acute respiratory infection and pneumonia due to indoor smoke in Dhading.J Nepal Heal Res Counc. 2010; 8:1-4.

3. Sherchand JB, Cunliffe NA, Tandukar S, Yokoo M, Pandey BD, Niraula P et al. Rotavirus disease burden and molecular epidemiology in children with acute diarrhea age less than 5 Years in Nepal. J Nepal Paediatr Soc. 2011;31(3):209-215.
4. Feachem RG. Bull WHO. Switzerland: World Health organization. 1984;62(3);467-476.

5. Department for Education and Skills. Planning for a human influenzapandemic.Guidanceto schoolsand children's services [Internet]. London: Department for Education and Skills. 2006[Assessed on 27 July 2011]. Available at: https://www.education.gov. uk/publications/eOrderingDownload/STERL-0706WEB.pdf.

6. Ministry of Health and Population. Nepal Health Sector Programme II (NHSP II) 2010-2015. Kathmandu: Ministry of Health and Population, Government of Nepal. 2010;p.58-59. 
7. Population division, Ministry of Health and Population (MoHP), Government of Nepal. Housing Characteristics and Household Population. In: New ERA and Macro International Inc. Nepal Demographic and Health Survey (NDHS) 2011. Kathmandu: Ministry of Health and Population, New ERA, and Macro International Inc. 2011:p.14 $-16$.

8. Lopez QC. Hand washing among school children in Bogotá, Colombia. Am J public Health. 2009 Jan;1999(1):94-101.

9. Oyibo PG. Basic personal hygiene: knowledge and practices among school children aged 6-14 years in Abraka, Delta state, Nigeria. Continental J Tropical Medicine. 2012;6(1):5-11.

10. Mohammed G, Nihar D, Bashayer A, Hiba I, Rasha A, Zaid AS. Knowledge and practice of personal hygiene among primary school students in SharjahUAE.J Health Sci. 2016;6(5):67-73.

11. Alyssa V, Bizu G, Nigusu A, Abera K, Yemane B, Michelle AW. Knowledge, attitudes, and practices (KAP) of hygiene among school children in Angolela, Ethiopia.J Prev Med Hyg. 2010 J une;51(2):73-79.
12. Gawai PP, Sachin A, Taware, Ameeta S, Thakur HP. A cross sectional descriptive study of hand washing knowledge and practices among primary school children in Mumbai, Maharashtra, India. Int J Community Med Public Health. 2016 Oct;3(10):2958-66.

13. Ray SK, Amarchand R, Srikanth J, Majumdar KK. Study on prevalence of bacteria in the hands of children and their perception on hand washing in two schools of Bangalore and Kolkata. Indian J Pub Health. 2011; 55(4):293-297.

14. Takalkar AA, Nirgude AS, Nagaraj K, Naik PR, Prasad VG, Rashmi SS. Hand hygiene perception and practices of school going children from rural Government schools of Nalgonda, Andhra Pradesh. Int J of Medical and Health Sci. 2013;2(2):154-160.

15. Ebong RD. Environmental health knowledge and practice survey among secondary school children in Zaria, Nigeria. Nigeria:Environment Health Perspective. 1994 Mar;102(3):310-2.

16. UNICEF. WASH program aligning for action: Sanitation and water for all in the context of climate change in Nepal. Nepal: WASH section, UNICEF. 2008;1-2. 